\title{
The distribution and seasonal availability of surface water on the Manyeleti Game Reserve, Limpopo Province, South Africa
}

\author{
H.P. Cronje, I. Cronje and A.J. Botha
}

Cronje, H.P., I. Cronje \& A.J. Botha. 2005. The distribution and seasonal availability of surface water on the Manyeleti Game Reserve, Limpopo Province, South Africa. Koedoe 48(2): 11-21. Pretoria. ISSN 0075-6458.

\begin{abstract}
The availability and abundance of surface water on the Manyeleti Game Reserve was quantified to provide information towards the development of a water provision policy. A total of 696 water source sites were located with a mean distance of $223.3 \mathrm{~m}$ apart. The water source sites (natural and artificial) were monitored seasonally to describe the seasonal availability of surface water on the Manyeleti Game Reserve. There were significant relationships between seasonal rainfall and the number of water source sites and maximum distance between sites. The large number of water sources is regulated by climatic progression and thus water provision on the Manyeleti Game Reserve follows a natural cycle linked primarily to rainfall. Water sources that dry up towards the dry seasons need to be supplied with water during drought periods in order to maintain game numbers without causing rangeland degradation. A water provision model that incorporates all the variables of the Greater Kruger Park Conservation Area, with particular reference to the smaller conservation areas within it, should become a research priority.
\end{abstract}

Key words: Surface water, water distribution, water sources, seasonal availability, Greater Kruger Park Conservation Area.

H.P. Cronje $\triangle$., I. Cronje \& A.J. Botha, Department of Nature Conservation, Tshwane University of Technology, Private Bag X680, Pretoria, 0001.

\section{Introduction}

Managers of protected areas have few effective methods at their disposal for controlling the movements of game. Water provision is one of the main interventions available to managers, along with a fire policy and population culling (Owen-Smith 1996). The availability and distribution of water sources can influence ecosystem structure and function at a range of scales and organisational levels through its influence on various processes and feedbacks affecting both animals and plants (Gaylard et al. 2003). Only the spatial and temporal variability of artificial water sources (such as boreholes) can be controlled by reserve management. Natural water sources vary over space and time in relation to various environmental factors. Broadscale heterogeneity in surface water availability and distribution is caused by geology (Gaylard et al. 2003). Fine-scale heterogeneity in surface water availability and distribu- tion is caused by rainfall patterns that vary over decades (wet and dry periods), years (El Niño oscillations) and seasons (Gaylard et al. 2003). Water persistence is additionally influenced by evaporation rates (Gaylard et al. 2003). The size of a conservation area will relate to the effects surface water availability and distribution will have on the area's spatial and temporal heterogeneity. The smaller the area, the more intensely it needs to be managed (Bothma 1996), because such areas are not self-regulating (Trollope 1990). Therefore, cognizance of the distribution, abundance, availability and the efficient maintenance of surface water (natural and artificial) are of paramount importance, as these factors have a profound influence on effective veld and game management (Young 1992).

The history and development of water provision in the Kruger National Park and the recent revision of the present policy are dis- 
cussed by Pienaar (1970) and Pienaar et al. (1997). Gaylard et al. (2003) also discussed the associated implications of water provision for heterogeneity and ecosystem processes. The provision of water in conservation undertakings, in principle, aims to support herbivore populations during dry seasons especially drought periods and in doing so also minimises the influence of temporal variability in rainfall (Gertenbach 1980; Gaylard et al. 2003). This was the driving thrust of the initial water provision policy of the Kruger National Park (Pienaar 1970; Pienaar et al. 1997). Several studies in the Kruger National Park have documented the piosphere effect (Lange 1969) that dictate the impact of water provision on both the herbaceous and woody components of vegetation (Van der Schijff 1959; Thrash et al. 1991a; Thrash et al. 1991b; Thrash et al. 1993; Thrash \& Derry 1999; Gaylard et al. 2003). These effects become apparent, particularly during the dry season (Redfern 2002). Zambatis (1980) indicated that waterpoints in the Klaserie Private Nature Reserve should not be closer than $5 \mathrm{~km}$ to one another in order to prevent range degradation and homogenisation of vegetation through coalescing of piopheres. Deleterious effects on game populations due to the injudicious provision of water have been documented for both the Kruger National Park as well as for the Klaserie Private Nature Reserve (OwenSmith 1996). The increase in the number of water points, particularly in areas naturally devoid of water, can lead to the increase in the populations of water-dependant species such as zebra and blue wildebeest. This increase in game numbers in relation to increased water availability, during drought periods, can lead to potentially catastrophic game mortalities as a result of overgrazing (Walker et al. 1987; Owen-Smith 1996; Gaylard et al. 2003). Thus abundant water supplies may support increased stocking levels but at the cost of the populations' ability to survive severe droughts (Owen-Smith 1996). An indirect implication of water provision is also the potential loss of rare species by predation (Harrington et al 1999), as a result of an increase in the densities of water depen- dant prey species in areas naturally devoid of water (Owen-Smith 1996; Gaylard et al. 2003).

The value of a water policy based on conservation, the judicious placement and utilisation of water resources and habitat protection is apparent under drought conditions (Zambatis 1980). Due to financial constraints, the management of the Manyeleti Game Reserve have been incapable of maintaining any artificial water sources. Therefore, a study investigating the water availability and distribution on the Manyeleti Game Reserve was needed in formulating a water provision policy. The eastern and southern fence-lines of the Manyeleti Game Reserve were dropped in 1996, creating an open conservation area, with definite management implications. Tourism is the driving objective of the Manyeleti Game Reserve. The inability to provide surface water during dry months and severe droughts will lead to the loss of game to adjacent conservation areas and so fail to realise the reserve's tourism objective.

The aim of this study was to assess whether water provision was a necessary management option in the Manyeleti Game Reserve to prevent wildlife from leaving the reserve during extended drought periods. The objectives were: to determine the number of water sources; to calculate the distance that herbivores had to traverse to locate water and how this distance varied through the course of the dry season; and to investigate the causes of surface water variability in the Manyeleti Game Reserve.

\section{Study Area}

The Manyeleti Game Reserve has a surface area of approximately 22700 ha and is situated adjacent to the Kruger National Park, between $24^{\circ} 42^{\prime}-24^{\circ} 23^{\prime} \mathrm{S}$ and $31^{\circ} 23^{\prime}-31^{\circ} 36^{\prime} \mathrm{E}$. The reserve is open to both the Kruger National Park to the east and the Sabie Sands Private Nature Reserve to the south (Fig. 1).

Bredenkamp et al. (1983) and Bredenkamp (1985) described the location, climate, topography and soils of the area. Bre- 


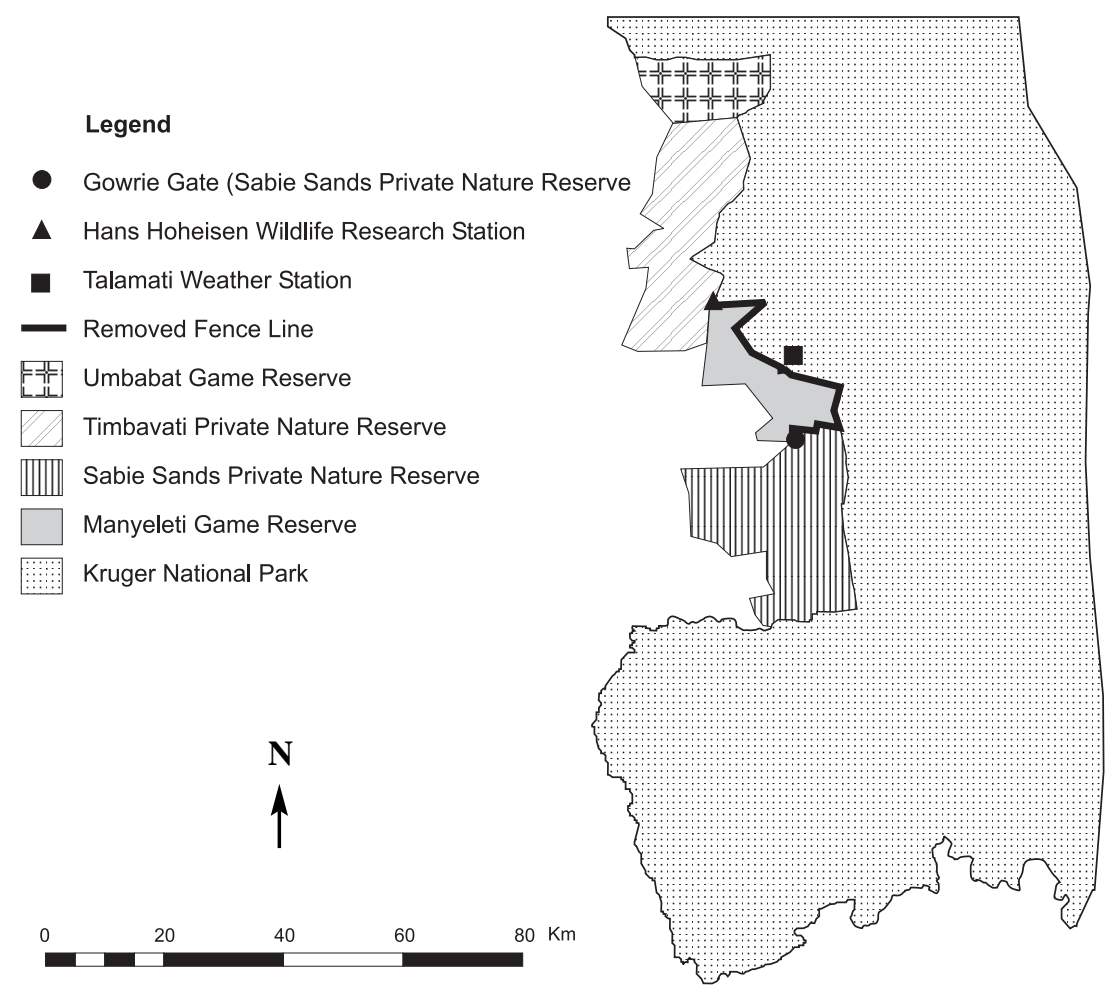

Fig. 1. The location of the Manyeleti Game Reserve in the Greater Kruger National Park Conservation Area.

denkamp (1982) classified and described the vegetation of the Manyeleti Game Reserve into seven main plant communities, viz.:

Perotis patens/ Terminalia sericea community occurring on granite derived soils; Euclea divinorum/ Acacia nigrescens community occurring on granite derived soils;

Themeda triandra/ Acacia gerrardii community occurring on granite derived soils;

Euclea divinorum/ Albizia harveyi community occurring on granite derived soils;

Themeda triandra/ Setaria incrassata community occurring on gabbro derived soils;

Cardiospermum corundum/ Acacia nigrescens community occurring on rocky hillocks;

Spirostachys africana/ Diospyros mespiliformis community occurring along the rivers.

The annual average rainfall for the area varies from 450-600 mm (Bredenkamp et al. 1996). The average medium-term (1990 to

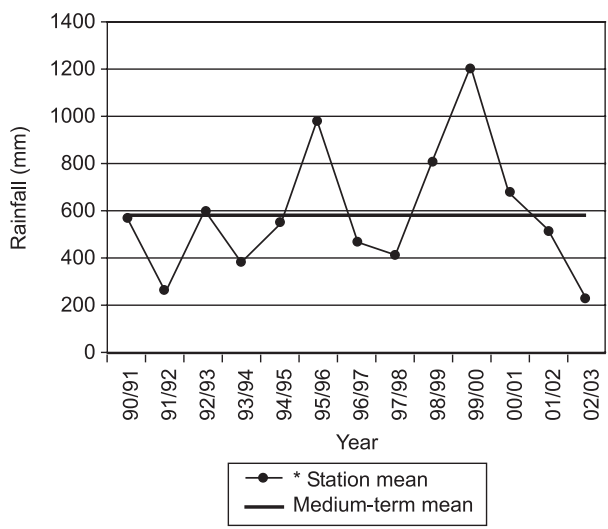

* Mean rainfall of the weather stations: Hans Hoheisen Wildlife Research station, Talamati and Gowrie Gate.

Fig. 2. Medium-term rainfall (13 years) recorded at three weather stations in close proximity to the Manyeleti Game Reserve. 


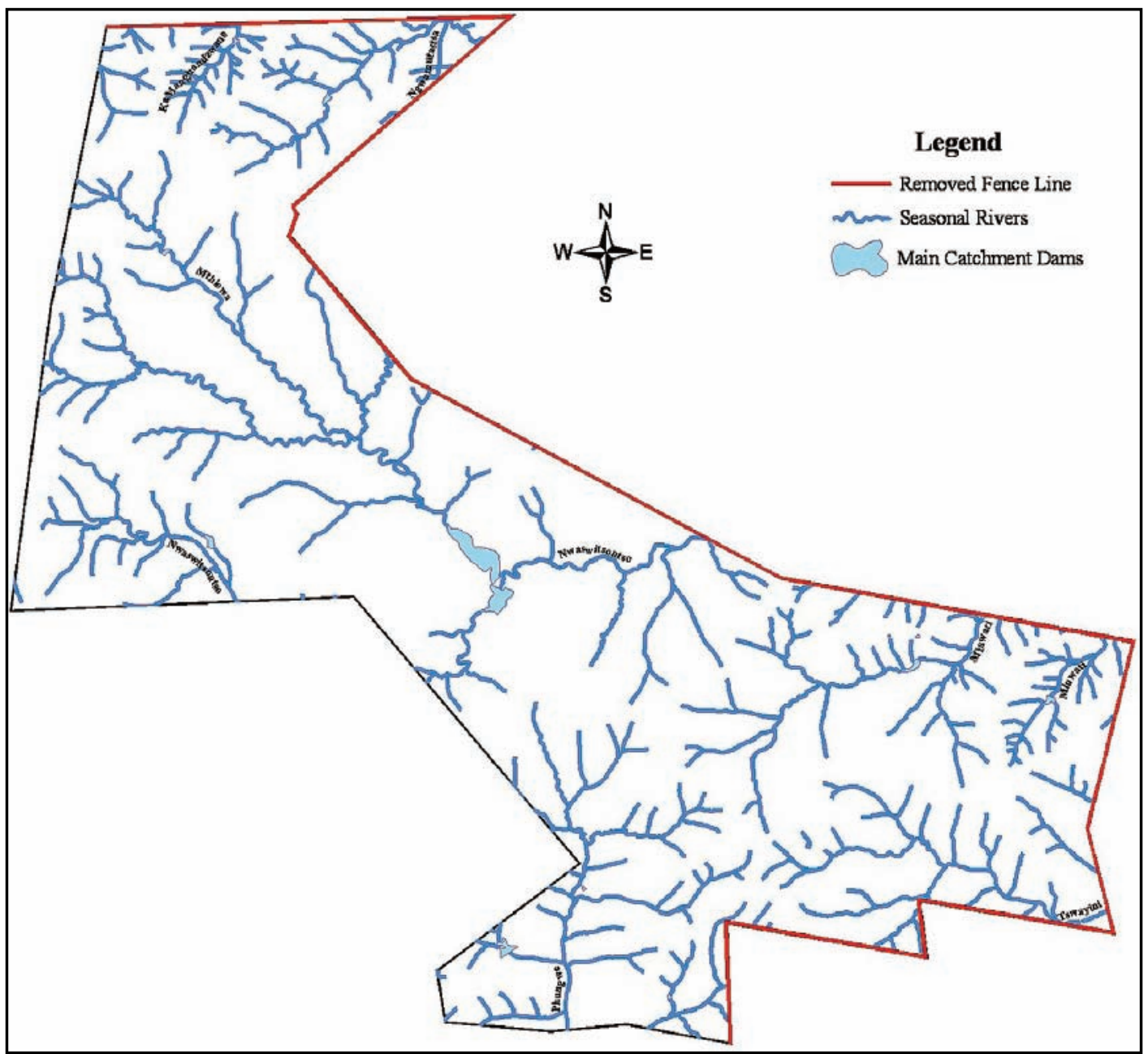

Fig. 3. The seven seasonal rivers that traverse the Manyeleti Game Reserve.

2003) rainfall calculated from three weather stations (Fig.1) for the Manyeleti Game Reserve is 590.4 mm (Fig. 2).

Seven seasonal rivers traverse the Manyeleti Game Reserve (Fig. 3), viz., the Nwaswitsontso, Mluwati, Tswayini, Phungwe, Mthlowa, Ngwamutastsa and KaManghondzwane.

The full component of herbivores and predators are accommodated on the Manyeleti Game Reserve. The mobile water-dependant species (white rhinoceros; blue wildebeest; Burchell's zebra; elephant; buffalo) and nonmobile water-dependent species (impala; waterbuck; warthog) have the greatest impact on the formation of additional surface water resources and the utilisation of savanna areas (Grossman et al. 1999) in the wet and dry seasons respectively. Mobile and non-mobile water dependant game are generally defined based on the distances that they are capable of ranging from permanent surface water (Grossman et al. 1999). The 
densities of non-mobile water dependant species decline appreciably beyond $\pm 5-6 \mathrm{~km}$ from permanent water. Mobile water dependant species are those that require drinking water regularly but which are able to range fairly far $(10 \mathrm{~km})$ from sources of water (Grossman et al. 1999).

\section{Methods}

The study needed to identify all surface water, thus it was decided to traversed the study area on foot to accurately locate and map the water sources. The road network and rivers were used to divide the area into sections to allow the accurate and systematic location of water sources within a section. These divisions were traversed on foot with the use of six observers spaced $30 \mathrm{~m}$ apart. Parallel transects were maintained with the aid of a compass.

A 1:50 000 topographic map was used to initially plot the location of each water source. Water sources that were closer than a $50 \mathrm{~m}$ radius of one another were allocated the same geographical co-ordinates. With this, water source sites were created. At each water source, the site location with the aid of a Global Positioning System (GPS) was recorded, as well as each water source's category (natural pan, river pool, trough, artificial dam, catchment dam or burrow pit); permanence and water supply (rainfall, runoff and pump). These were quantified because the distances between water points are influenced by both natural and artificial sources of water. The water sources were monitored annually for the years 2000, 2001 and 2002, respectively, at the end of the wet (throughout May) and dry (throughout August) seasons.

The final cartography and spatial analysis of the distribution of the water sources was done with a Geographical Information System (GIS). Rainfall data (i.e., the seasonal mean) used in the data analysis were collected from the Hans Hoheisen Wildlife Research Station, the Talamati weather station and the Gowrie gate of the Sabie Sands Private Nature Reserve (Fig. 1). The functional relationship of the number and maximum distances between water source sites relative to the seasonal rainfall was tested by means of linear regression $(y=b+m x)$ analyses (Zar 1996). The null hypothesis was rejected if $P \leq 0.05$. Significant relationships were taken to be sufficient evidence to conclude that rainfall was the determinant factor effecting the seasonal number and distance between water sources on the Manyeleti Game Reserve. A comparison of regression between rainfall of the previous three years (i.e., before 2000) and that of the current season (2000, 2001 and 2002) was assessed to validate the variability of surface water on the Manyeleti Game Reserve.

\section{Results}

The initial locating of the water sources started in June 1999 and ended in May 2000. Eight hundred and seventy water sources were found on the Manyeleti Game Reserve. The distribution of surface water is represented across 696 surface water sites (Fig. 4; Table 1). The difference is clarified by the

Table 1

The total number and distances between water source sites according to seven water sources categories on the Manyeleti Game Reserve

\begin{tabular}{lcccc}
\hline Category & $n$ & Mean Distance $(\mathrm{m})$ & Min. Distance $(\mathrm{m})$ & Max. Distance (m) \\
\hline Artificial dams & 32 & $1290.7( \pm 100.4)$ & 104.2 & \\
Catchment dams & 13 & $2686.4( \pm 467.7)$ & 1936.3 & 3375.7 \\
Natural pans & 551 & $235( \pm 182.8)$ & 27.9 & 1100.3 \\
Borrow pits & 36 & $1176.3( \pm 728.1$ & 83.4 & 3065.6 \\
River pools & 46 & $519.9( \pm 828.2)$ & 41.7 & 3811.4 \\
Troughs & 17 & $1833.4( \pm 1134.6)$ & 216.9 & - \\
Flood plain & $* 1$ & - & - & 1450.4 \\
\hline Total & 696 & $223.3( \pm 181.2)$ & 27.9 & \\
\hline
\end{tabular}

*No distance measurements 


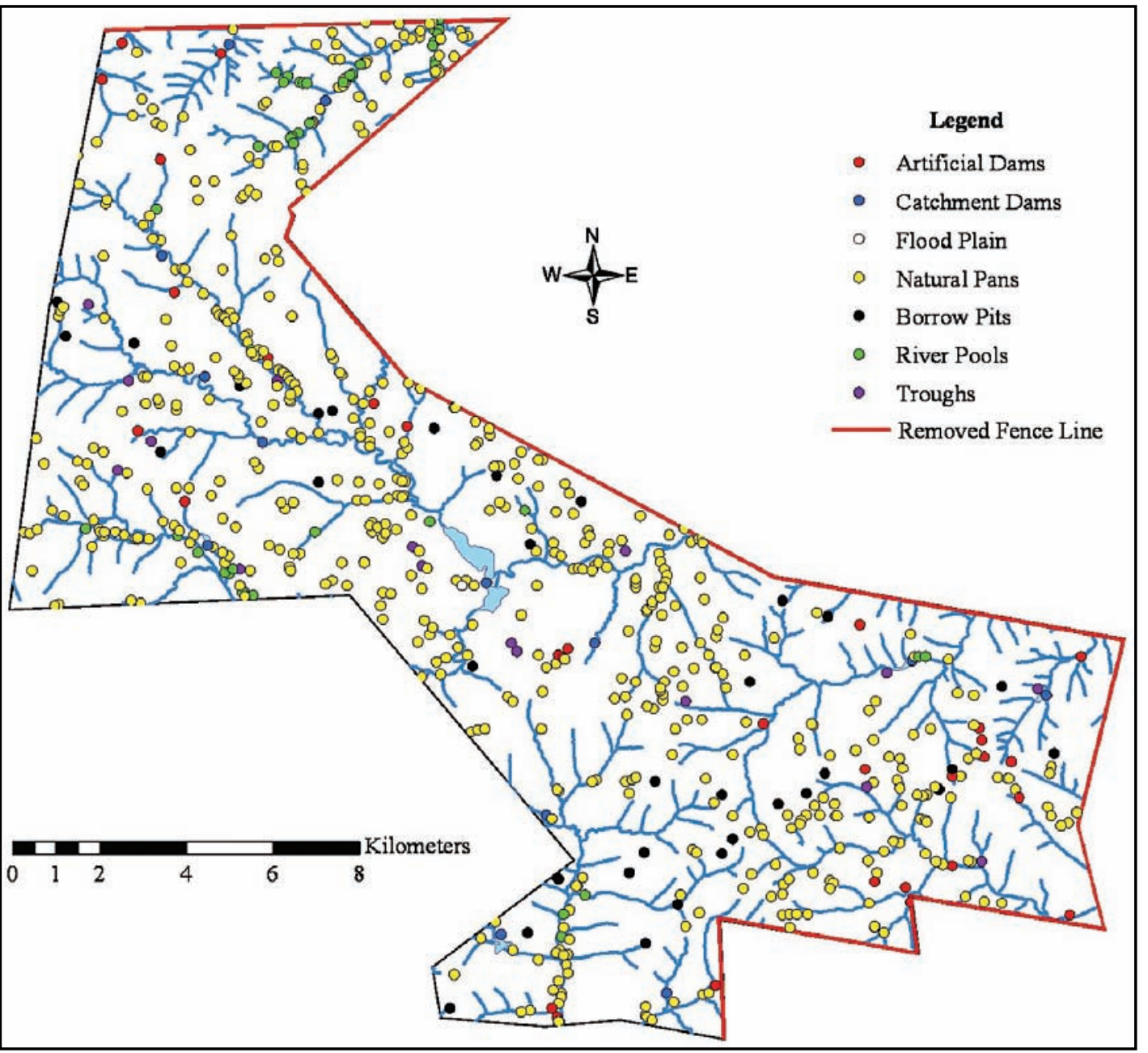

Fig. 4. The distribution of surface water on the Manyeleti Game Reserve.

fact that in several cases more than one water source occurred at a particular site represented by a geographical co-ordinate. This was predominately the case with the natural pans. The proportion of water sources in the broad natural and man-made surface water categories were $87.2 \%$ and $12.8 \%$, respectively (Table 2). The mean distance between all the water source sites was $223.3 \mathrm{~m}( \pm 181.2 \mathrm{~m})$ with the shortest and longest distances being $27.9 \mathrm{~m}$ and $1450 \mathrm{~m}$ accordingly (Table 1 ).

There was a significant $(P=0.003)$ relationship between the number of water sources and the current season's rainfall (Fig. 5), thus indicating that seasonal rainfall was the predominant cause of the number of water sources that held water during the study period. Distance, as a measure of water availability to game, had a descriptive relationship (in terms of the minimum, mean and maximum distances between water sources) with the seasonal rainfall. The distance between water sources increased as seasonal rainfall decreased, with the converse also apparent (Fig. 6). No significant relationship was found between minimum $(P=0.34)$ and mean distance $(P=0.22)$ with seasonal rainfall. A significant relationship $(P=0.04)$ was, 
Table 2

Water source contribution proportions within the broad natural and man-made categories

\begin{tabular}{lcccccc}
\hline & \multicolumn{2}{c}{ Natural } & \multicolumn{4}{c}{ Man-made } \\
& NP & RP & A & CD & B & T \\
\hline Total & 699 & 62 & 34 & 15 & 44 & 19 \\
$\begin{array}{l}\text { Proportion } \\
\text { (\%) }\end{array}$ & 87.2 & & 12.8 & \\
\hline
\end{tabular}

however, found between the maximum distance between water sources and seasonal rainfall (Fig. 7). The incorporation of the seasonal rainfall data of the previous 3 years into the data set to quantify the cumulative effect of rainfall on the current season's surface water availability was not significant $(P>0.05)$. This indicated that water availability on the Manyeleti Game Reserve is primarily regulated by the current and preceding year's rainfall. The mean distance ( $572.3 \mathrm{~m} \pm 478.2 \mathrm{~m}$ ) between water sources at the end of the dry season of 2000 (August) can be attributed to the high rainfall (1206.2 mm) during its current wet season

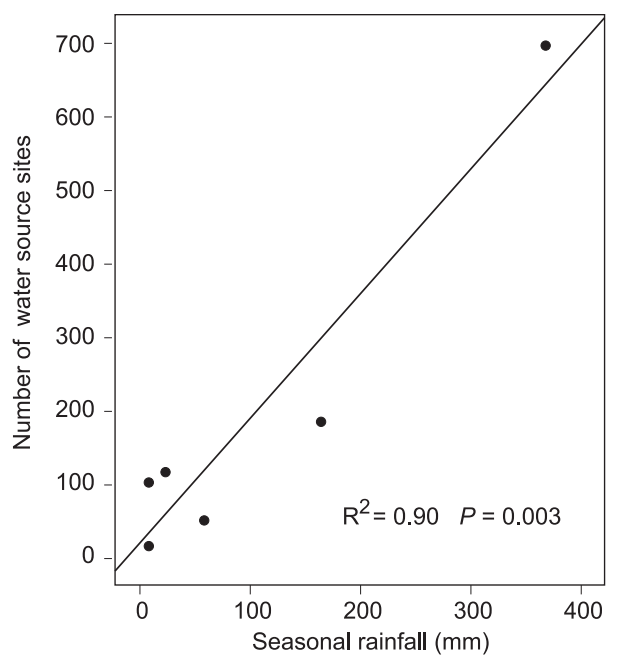

Fig. 5. The significant linear relationship between the number of water source sites and seasonal rainfall in the Manyeleti Game Reserve.

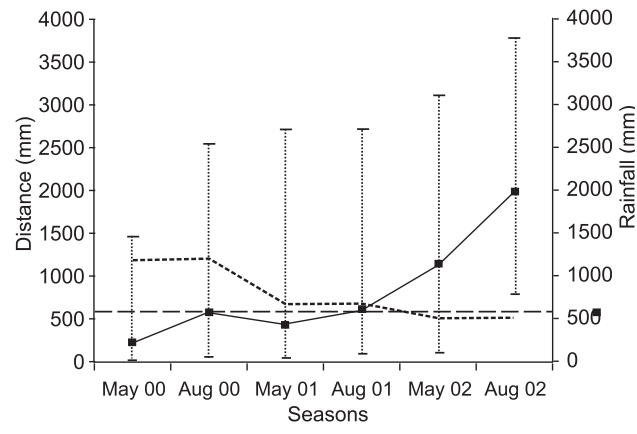

$$
\begin{aligned}
& \text { - Mean distance } \\
& \text { - Min. distance } \\
& \text { - Max. distance } \\
& \text {--- Rainfall } \\
& \text { - } \text { Mean medium-term rainfall }
\end{aligned}
$$

Fig. 6. Descriptive relationship of distances between water source sites and seasonal rainfall in the Manyeleti Game Reserve.

and the above-average rainfall of the previous year's wet season (804.7 mm) (Fig 6). The mean water source site spacing at the end of the wet and dry season for 2001 was $436.3 \mathrm{~m}( \pm 404.3 \mathrm{~m})$ and $597.7 \mathrm{~m}( \pm 478.2 \mathrm{~m})$. The surface water availability is attributed

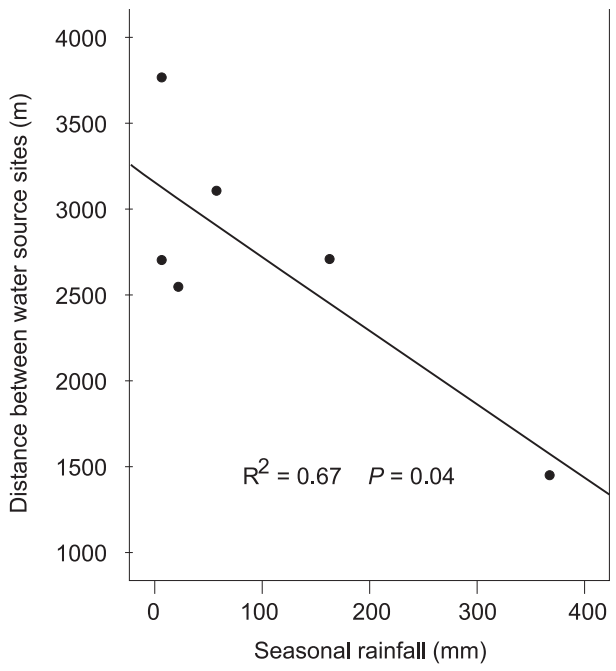

Fig. 7. The significant linear relationship between the maximum distance between water source sites and seasonal rainfall. 
Table 3

Distances between artificial water sources for the dry seasons of 2000, 2001 and 2002

\begin{tabular}{lcccc}
\hline Year & $n$ & Mean $\frac{\text { distance }(\mathrm{m})}{\mathrm{X}} \pm \mathrm{SD}$ & Min. distance $(\mathrm{m})$ & Max. distance $(\mathrm{m})$ \\
\hline Aug. 2000 & 49 & $1056.5( \pm 656.5)$ & 154.9 & 2556.2 \\
Aug. 2001 & 48 & $1130( \pm 671)$ & 228.2 & 2917.4 \\
Aug. 2002 & 15 & $2280.2( \pm 1103.2)$ & 873.8 & 4194.1 \\
\hline
\end{tabular}

to the high rainfall (1206.2 mm) of the 1999/ 2000 wet season and an above average $(676.2 \mathrm{~mm})$ rainfall for the wet season of 2000/2001 (Fig. 6). The increase in the distance between the water sources for 2002 at the end of the wet and dry season to $1131 \mathrm{~m}$ $( \pm 776.1 \mathrm{~m})$ and $1994.2 \mathrm{~m}( \pm 978.2 \mathrm{~m})$, respectively, can thus be attributed to the rainfall of 2000/2001 and 2001/2002 that were above $(676.2 \mathrm{~mm})$ and below $(516.3 \mathrm{~mm})$ the mean medium-term rainfall for the Manyeleti Game Reserve (Fig. 6). The average dry season distance between the man-made water sources (semi-permanent) ranged between $1056 \mathrm{~m}( \pm 656.5 \mathrm{~m})$ and $2280.2 \mathrm{~m}( \pm 1103.2 \mathrm{~m})$ (Table 3).

\section{Discussion}

It is evident from the results that rainfall was the primary determinant of surface water availability. Years of high rainfall resulted in a large number of water source sites with water within close proximity to one another. With rainfall decreasing to below average, so the number of water source sites with water decreased, causing an increase in the distance between the water sources. The inability to find a significant relationship between the minimum and mean distances of water sources with seasonal rainfall could possibly be attributed to the large number of water sources (i.e. mostly within the natural water source category) that had several close distances measured between sites. This was clearly demonstrated in Fig. 6 where the mean distance was biased towards the minimum and not representative of the maximum distances measured in this data set.
The factors that have been shown to affect the availability of surface water in the Kruger National Park are primarily rainfall and secondary factors such as geology and evaporation (Gaylard et al. 2003). In this study, the influence of rainfall on the persistence of surface water was primarily influenced by the rainfall of the previous year and the current season. It was not the cumulative effect of rainfall seasons longer than a year. In contrast, the cumulative influence of previous years' rainfall determine the persistence of river pools in the Kruger National Park (Gaylard et al. 2003), this could possibly be linked to the variability of depth of the water table during the periods of below and above average rainfall. With the exception of the catchment dams, the water sources on the Manyeleti Game Reserve are away from rivers. The geology of the Manyeleti Game Reserve is largely homogeneous and thus differences in water availability relative to geology could not be ascribed. The soils are predominantly of granitic origin (Walraven 1986) and thus water loss through drainage could also be seen as a factor that determined water persistence through the dry season on the Manyeleti Game Reserve. Surface water in the Kruger National Park persist longer on the clayey basaltic soils in the east in contrast to the lower persistence of surface water on the more permeable granitic soils in the west (Gaylard et al. 2003). Evaporation rates, although not examined, could also have been an additional factor that could have influenced the persistence of water sources on the Manyeleti Game Reserve.

With 696 sites at which water can be found after above-average to high wet season rainfall, water is abundant with minimal range 
deterioration around any single water source. Water-dependant herbivores typically show wet season dispersal into areas removed from perennial water sources and thus the vegetation near water is relieved of severe grazing pressure during this period (OwenSmith 1996). Conversely, as the availability of water sources decrease so the grazing pressure around the remaining water sources increase (Young 1992; Thrash \& Derry 1999; Redfern 2002). This becomes more severe under drought conditions, particularly where permanent water-points are excessively close to one another resulting in starvation-induced mortalities which are attributed to reductions in forage capable of supporting high game densities (Owen-Smith 1996). Game mortalities of this nature have occurred and been documented in the Klaserie Private Nature Reserve (Walker et al. 1987) and the central regions of the Kruger National Park (Gaylard et al. 2003). Studies suggest that the average distance between surface water points should be $\geq 5 \mathrm{~km}$ in medium-sized nature reserves (Zambatis 1980), e.g., Manyeleti Game Reserve, and 15-30 km in extensive areas (Collinson 1983; Owen-Smith 1996) such as Kruger National Park, to prevent starvation. The mean dry-season distance between the man-made water sources (semi-permanent) varied between $1056 \mathrm{~m}$ and $2280 \mathrm{~m}$. The Manyeleti Game Reserve is a small to medium-sized conservation area and thus spacing of less than $5 \mathrm{~km}$ could have deleterious effects on its vegetation. This would be a point of concern if the Manyeleti Game Reserve was a closed system (i.e. fully fenced). Fortunately, it is a semi open system, open to the Kruger National Park and the Sabie-Sands Private Nature Reserve (Fig. 1). Game can move freely between the conservation areas and thus the effect of game densities relative to the distance between water sources is not as adverse as in an enclosed conservation system. The availability of surface water on the Manyeleti Game Reserve is dependant on rainfall and runoff. Temperature, rainfall and evaporation regulate the abundance of this surface water. Water is abundant in the wet season and becomes more widespread during the dry season. Thus in essence the availability and distribution of surface water conforms to a natural cycle and is favourable as it facilitates a natural rotational grazing sequence, relieving areas that have been over utilised as the water sources dry up.

\section{Conclusion}

The seasonal availability of water sources on the Manyeleti Game Reserve (natural and man-made) appears to conform to a natural regulating process influenced primarily by rainfall and possibly evaporation. The availability of surface water declines through the dry season, providing a natural sequence of game movement and reducing the pressure of grazing around water sources as they dry up. This scenario is favourable because the financial implications of maintaining a large number of artificially supplied dams by windmill or mechanical pump is reduced.

The primary objective of the Manyeleti Game Reserve is tourism. Water points would thus promote this objective. Water points can provide focal game viewing points for tourists, thus contributing to the attractiveness of a park and thereby enhancing the economic viability of protected areas (Owen-Smith 1996). Management intervention will be required during severe drought periods within the natural cycle of providing water in order to achieve the tourism objective. During the dry season of 2003, only one dam provided water in the central region of the Manyeleti Game Reserve. Apart from game being in close proximity to this dam, game viewing in northern and southern parts of the reserve was generally poor. Management needs to maintain a wide variety of game species in sufficient numbers to achieve the game viewing experience of the visitor. Thus the Manyeleti Game Reserve will require the active provision of artificial water in order to prevent the loss of game species to adjacent conservation areas. In order to identify the optimum density of active artificial water supply, it is essential to understand the effect the large number of 
water sources have had on the vegetation of the Manyeleti Game Reserve. A study is currently being done to quantify the piosphere effect around several water sources (both natural and artificial). This will provide answers towards the optimum number and spacing of water sources during the dry and drought periods in order to promote tourism and sustainable vegetation management.

The management of multi-species systems, e.g. Manyeleti Game Reserve and adjacent conservation areas, has numerous components and variables of which many of them are poorly quantifiable and subject to stochastic variability (Grossman et al. 1999). Conservation areas that have contributed to the formation of the Greater Kruger Park Conservation Area (GKPCA) through fence removal have important management implications to consider in the compilation of water provision policies relative to the smaller conservation areas within the GKPCA. Open small and medium-sized conservation areas cannot adopt water provision policies alien from the larger conservation areas. The development of water provision policies of the small conservation areas need to be done within the context of the multi-system of which they are apart. This is of paramount importance if the management objectives of any single conservation area are to be achieved. A water provision model that incorporates all the variables of the GKPCA, with particular reference to the smaller conservation areas, should become a research priority.

\section{Acknowledgements}

The authors would like to express their sincere gratitude to the field rangers of the Manyeleti Game Reserve for their devoted assistance and perseverance during the initial locating of the water sources. Sandra Macfadyen (GIS Technician, Kruger National Park) is especially thanked for her valuable advice regarding the statistical analysis of the water source data in this paper. Special thanks to the referees for their valuable guidance in the final compilation of this paper.

\section{References}

BothMA, J DU P. 1996. Important ecological principles. Pp. 7-25. In: BотнмA, J DU P. (ed.). Game Ranch Management. Pretoria: Van Schaik.

BRedenKAMP, G.J. 1982. 'n Plantekologiese studie van die Manyeleti-wildtuin. D.Sc. tesis, Universiteit van Pretoria, Pretoria.

Bredenkamp, G.J., G.K. Theron \& D.R.J. van VUUREN. 1983. Ecological interpretation of plant communities by classification and ordination of quantitative soil characteristics. Bothalia 14:691-699.

BREDENKAMP, G.J. 1985. An evaluation of the relative importance of certain habitat factors that influence the distribution of the plant species of the Manyeleti Game Reserve. South African Journal of Botany 51(3): 194-196.

Bredenkamp, G., J.E. Granger \& N. VAN RoOyen. 1996. Mixed Lowveld Bushveld. Pp. 27. In: Low, A.B. \& A.G. ReBelo (eds.). Vegetation of South Africa, Lesotho and Swaziland. Pretoria: Dept. Environmental Affairs \& Tourism.

Collinson, R. 1983. Pilanesberg's policy on providing artificial water points for game. Part 4: The implications of providing artificial water points indiscriminately. Tshomarelo News 13: 17-26.

Gaylard, A., N. OWEn-Smith \& J.V. Redfern. 2003. Surface water availability: Implications for heterogeneity and ecosystem processes. Pp. 171-188. In: Du ToIT, J.T., K. H. Rogers \& H. C. BIGgs. (eds). The Kruger experience: Ecology and management of savanna heterogeneity. Washington: Island Press.

GertenBACH, W.P.D. 1980. Rainfall patterns in the Kruger National Park. Koedoe 23: 35-43.

Grossman, D., P.L. Holden \& R.F.H. Collison. 1999. Veld management on the game ranch. Pp. 261-279. In: TAINTION, N.M. (ed). Veld management in South Africa. Pietermarizburg: University of Natal Press.

Harrington, R., N. Owen-Smith, P.C. Viljoen, H.C. Biggs, D.R. Mason \& P. Funston. 1999. Establishing the causes of the roan antelope decline in the Kruger National Park, South Africa. Biological Conservation 90:69-78.

LANGE, R.T. 1969. The piosphere, sheep track and dung patterns. Journal of Range Management 22: 396-400.

OWEN-SMith, N. 1996. Ecological guidelines for water-points in extensive protected areas. South African Journal of Wildlife Research 26(4): 107-112.

Pienaar, D., H. Biggs, A. Deacon, W. Gertenbach, S. Joubert, F. Nel, L. VAN RoOyen \& F. VenTER. 1997. A revised water-distribution policy for biodiversity maintenance in the KNP. Pp. 165-200 In: BRAAK, L.(ed). A revision of parts of the management plan for the Kruger National 
Park. Volume VIII: Policy Proposals Regarding Issues Relating to Biodiversity Maintenance, Maintenance of Wilderness Qualities and Provision of Human Benefits. Unpublished internal report, South African National Parks, Skukuza, South Africa.

PienaAR, U. DE V. 1970. Water sources of the Kruger National Park. African Wildlife 24: 180-191.

REDFERN, J. V. 2002. Manipulating surface water availability to manage herbivore distributions in the Kruger National Park. PhD. dissertation, University of California, Berkely, USA.

Thrash, I., P.J. Nel, G.K. Theron \& J. Du P. BothMA. 1991a. The impact of the provision of water for game on the woody vegetation around a dam in the Kruger National Park. Koedoe 34(2): 131-148.

Thrash, I., P.J. Nel, G.K. Theron \& J. DU P. BothMA. 1991b. The impact of the provision of water for game on the basal cover of the herbaceous vegetation around a dam in the Kruger National Park. Koedoe 34(2): 121-130.

Thrash, I., G.K. Theron \& J DU P. Bothma. 1993. Impact of water provision on the herbaceous community composition in the Kruger National Park, South Africa. African Journal of Range and Forage Science 10: 31-35.
Thrash, I. \& J.F. DerRy. 1999. The nature and modelling of piospheres: a review. Koedoe 42(2): 73-94.

Trollope, W.S.W. 1990. Veld management with specific reference to game ranching in the grassland and savanna areas of South Africa. Koedoe 33(2): 77-87.

VAN DeR SchIJfF, H. 1959. Weidingsmoontlikhede en weidingsprobleme in die Nasionale Krugerwildtuin. Koedoe 2: 96-127.

WALKeR, B.H., R.H. EMSLIE, R.N. OWEN-SMith \& R.J. SchOLES. 1987. To cull or not to cull: lessons from a southern African drought. Journal of Applied Ecology 24: 381-401.

Walraven, F. 1986. 2430 Pilgrim's Rest 1: 250000 Geological Series. Pretoria.Government Printer.

Young, E. 1992. Game farming and wildlife management. Nylstroom: Eddie Young Publishers.

Zambatis, N. 1980. Water provision in the Klaserie Private Nature Reserve. Project TN 6/4/1/29. Second and Final Report. Nature Conservation Division: Transvaal Provincial Administration. Hans Hoheisen Wildlife Research Station.

ZAR, J.H. 1996. Biostatistical analysis. New Jersey: Pentice-Hall. 
